\title{
Analisa Total Productive Maintenance (TPM) Menggunakan Overall Equipment Effectiveness (OEE) Pada Mesin CNC Milling
}

\section{Total Productive Maintenance Analysis to Measure the Overall Equipment Effectiveness (OEE) on a CNC Milling Machine}

\author{
${ }^{1}$ Dian F. Hidayat, ${ }^{2}$ Joko Hardono, ${ }^{3}$ Wahyu Argi Wijaya \\ ${ }^{1}$ Universitas Muhammadiyah Tangerang, JL.Perintis Kemerdekaan I no.33 Cikokol Tangerang \\ ${ }^{2}$ Universitas Muhammadiyah Tangerang, JL.Perintis Kemerdekaan I no.33 Cikokol Tangerang \\ ${ }^{3}$ Universitas Muhammadiyah Tangerang, JL.Perintis Kemerdekaan I no.33 Cikokol Tangerang \\ e-mail : ${ }^{1}$ Dianfriana@gmail.com, ${ }^{2}$ jhardono@yahoo.com, ${ }^{3}$ wahyu.agi01@gmail.com
}

\begin{abstract}
PT. JNA is engaged in the packaging machinery industry with products produced, namely semi automation, full automation packaging machines, gallon filling machines, etc. The production process of spare parts and their spare parts is through a CNC lathe machine and a CNC Milling machine. The observations on the MV40 CNC Milling machine process because of the higher amount of downtime. The method used in this research is Overall Equipment Effectiveness (OEE) to measure the effectiveness of the MV40 CNCMilling machine. From the calculation results show the average value of the effectiveness level of the MV40 CNC Milling machine in the period December 2018 - November 2019 is $76.84 \%$. After that, the analysis was carried out using Pareto Diagram tools and Fishbone Diagrams. As a result, the alarm (emergency stop) axis $z$ over travel and the hydraulic pump motor is broken, which is the main factor causing the biggest downtime. The root causes of these problems include (Human: inexperience, ignorant / indifferent operators), (Method: No SOP) and from these data a design proposal for improvement using the $5 W+1 H$ method was made.
\end{abstract}

Keywords: Downtime, Overall Equipment Effectiveness (OEE), Diagram Pareto, Diagram Fishbone.

Abstrak

PT. JNA bergerak dalam bidang industri mesin kemasan dangan produk yang dihasilkan yaitu mesin packaging semi automation, full automation, mesin pengisian gallon, dan lainnya. Proses produksi sparepart dan suku cadangnya melalui mesin cnc lathe dan mesin $C N C$ Miling. Pengamatan dilakukan pada proses mesin CNC Miling MV40 karena jumlah downtime yang lebih lebih tinggi. Metode yang digunakan dalam penelitian ini adalah Overall Equipment Effectiveness (OEE) untuk mengukur efektivitas mesin CNC Miling MV40. Dari hasil perhitungan menunjukan nilai rata-rata tingkat efektivitas mesin CNC Miling MV40 pada periode Desember 2018 - November 2019 adalah $76.84 \%$. setelah itu dilakukan analisis menggunakan tools diagram pareto dan diagram fishbone. Hasilnya alarm (emergency stop) axis $\mathrm{z}$ over travel dan motor pompa hidrolik jebol, menjadi faktor penyebab utama downtime terbesar. Akar penyebab dari masalah tersebut diantaranya 1.Manusia : Kurang pengalaman, Operator cuek / tidak peduli, 2. Metode : Tidak ada SOP. Dari data tersebut dibuat rancangan usulan perbaikan dengan menggunakan metode $5 \mathrm{~W}+$ $1 \mathrm{H}$.

Kata Kunci: Downtime, Overall Equipment Effectiveness (OEE), Diagram Pareto, Diagram Fishbone. 


\section{PENDAHULUAN}

PT. JNA merupakan sebuah perusahaan yang bergerak dalam bidang industri pembuatan mesin kemasan dengan produk yang dihasilkan yaitu mesin packaging semi automation, full automation dan mesin pengisian gallon. Salah satu produk full automation yaitu mesin autocup digunakan untuk pengemasan produk minuman gelas plastik, pengemasan saus gelas, pengemasan coklat. Mesin tersebut terdiri dari beberapa komponen seperti body mesin, body panel, dan sparepart mesin. Body mesin terbuat dari plat stainless steel 304 dengan proses pemotongan bentuk pola dengan mesin CNC laser cutting, setelah itu proses penekukan dengan mesin bending, proses pengelasan untuk menyambungkan body, kemudian proses poles body agar dihasilkan body yang besih. Body panel hanya melawati proses penekukan dan poles. Setelah itu proses produksi sparepart seperti filing, filler cup, cup sealer, mold, photocell, plat pisau, dudukan servo menggunakan mesin CNC miling dan CNC bubut. Selanjutnya proses perakitan seluruh sparepart ke body dan perakitan panel dilanjutkan proses pengujian, pemeriksaan kualitas, dan diakhiri oleh proses pengemasan.

Diantara semua mesin yang digunakan, mesin $C N C$ milling merupakan mesin yang paling tinggi jam operasionalnya karena tidak hanya menghasilkan komponen yang dibutuhkan untuk perakitan mesin namun juga menghasilkan komponen cadangan sebagai pengganti komponen yang rusak karena umur pakai. Tingginya jam operasional mesin $C N C$ milling berpengaruh pada kinerjanya sehingga perawatan berkala perlu dilakukan agar kendala pada proses produksi tidak terjadi. Berdasarkan data dilapangan pada Desember 2018 hingga November 2019, perusahaan memiliki 5 mesin $C N C$ milling, diataranya $C N C$ miling Mori Seiki MV-40 memiliki nilai rata-rata downtime yang tinggi yaitu 47.567 jam setiap bulannya.

Salah satu pendekatan yang digunakan untuk menanggulangi permasalahan yang terjadi pada mesin CNC miling Mori Seiki MV-40 adalah dengan mengukur nilai Overall Equipment Effectiveness (OEE). OEE mengukur efektifitas secara total (complate, inclusive, whole) dari kinerja mesin terhadap pekerjaan yang sudah direncanakan, diukur dari data aktual terkait dengan availability, performance efficiency, dan quality of product (Williamson, 2006). (Nakajima, 1988) menyatakan bahwa availability rate menggambarkan pemanfaatan waktu yang tersedia untuk kegiatan operasi mesin. Performance rate menggambarkan berapa banyak produk yang dihasilkan selama waktu produksi. Quality rate merupakan suatu rasio yang menggambarkan kemampuan peralatan dalam menghasilkan produk yang sesuai dengan standar. Dari hasil perhitungan OEE akan digunakan untuk mengidentifikasi dan melakukan pengelompokan penyebab rendahnya kinerja dari peralatan. Adapun penilaian terkait dengan OEE mesin mengikuti standar global adalah $90 \%$ untuk nilai availability rate, 95\% performance rate, dan 99\% untuk quality rate atau 85\% untuk nilai OEE dari suatu peralatan.

Seperti yang dilakukan oleh (Habib \& Supriyanto, 2012) yaitu mengukur nilai overall equipment effectiveness (OEE) sebagai pedoman perbaikan efektivitas mesin CNC cutting pada perusahaan yang memproduksi boiler berjenis heat recovery system generator dan utility. Adapun hasil pengukurannya diperoleh yaitu availability rate adalah $84,9 \%$, performance rate sebesar $72,9 \%$, quality rate sebesar $100 \%$, dan OEE sebesar $61,8 \%$. Penyebab belum 
optimalnya nilai OEE mesin dilakukan analisa lebih lanjut dengan menggunakan tools seperti analisa akar masalah (Root Cause Analysis), FMEA (Failure Mode and Effect Analysis), dan AHP (Analytical Hierarchy Process). Analisa penerapan total productive maintenance menggunakan overall equipment effectiveness dan six big losses juga dilakukan oleh (Rinawati \& Dewi, 2014) pada mesin Cavitec di perusahaan pembuat filter PT. Essentra Surabaya, hasilnya menunjukkan bahwa rata-rata nilai OEE pada mesin Cavitec VD-02 sebesar $28,50 \%$, faktor terbesar yang mempengaruhi rendahnya nilai OEE adalah performance rate dengan faktor presentase six big losses pada idling and minor stoppages loss sebesar 41,08 \% dari total time loss.

Berdasarkan temuan dilapangan dan tinjauan pustaka maka tujuan yang ingin dicapai pada penelitian ini yaitu dan dapat menganalisa kondisi perawatan mesin, mengetahui faktor-faktor penyebab menurunnya efektifitas mesin.

\section{METODOLOGI PENELITIAN}

Bab ini menjelaskan tahapan didalam penelitian untuk mencapai tujuan yang telah dibuat dengan langkah-langkah yang jelas dan terukur sehingga penelitian dapat terlaksana secara efektif. Dimulai dari tinjauan lapangan dengan melakukan wawancara dan analisa data, kemudian tinjauan pustaka untuk memperoleh literature yang sesuai dengan permasalahan sehingga tujuan dapat dibuat. Adapun jenis data yang digunakan dan metode pengolahan serta analisanya yaitu sebagai berikut;

\subsection{Jenis Data}

a. Data Primer: Data yang diperoleh langsung dari sumbernya seperti wawancara

b. Data Sekunder: Data yang diperoleh berdasarkan laporan perusahaan seperti data hasil produksi, data produk cacat, data downtime, dan lainnya.

\subsection{Metode Pengolahan dan Analisa Data}

Dari data yang telah diperoleh, data-data tersebut diolah untuk memperoleh tingkat efektivitas mesin CNC miling dengan cara menghitung masing-masing nilai seperti Availability Rate, Performance Rate dan Quality Rate. Analisa menggunakan diagram pareto dan diagram sebab akibat kemudian usulan untuk perbaikan menggunakan $5 \mathrm{~W}+1 \mathrm{H}$.

\section{HASIL DAN PEMBAHASAN}

Untuk mengetahui efektivitas mesin CNC miling pada perusahaan maka perlu mengukur nilai Overall Equipment Effectiveness dengan cara mengkalikan semua parameter seperti Availability Rate, Performance Rate dan Quality Rate.Beberapa parameter tersebut dapat dihitung setelah data produksi, data downtime, data kualitas, diperoleh. Proses produksi yang dilakukan perusahaan selama jam kerja normal adalah 14 jam dalam sehari yang terdiri dari 2 shift. 
Tabel 1 Data Produksi dan Downtime Mesin CNC Milling MV40

Desember 2018 - November 2019

\begin{tabular}{lcccccc}
\hline Bulan & $\begin{array}{c}\text { Total } \\
\text { produksi } \\
\text { (pcs) }\end{array}$ & $\begin{array}{c}\text { Data } \\
\text { cacat } \\
\text { (pcs) }\end{array}$ & $\begin{array}{c}\text { Data } \\
\text { produk } \\
\text { bagus }\end{array}$ & $\begin{array}{c}\text { Total } \\
\text { Available } \\
\text { Time (menit) }\end{array}$ & $\begin{array}{c}\text { Downtime } \\
\text { terencana } \\
\text { (menit) }\end{array}$ & $\begin{array}{c}\text { Downtime } \\
\text { tidak terencana } \\
\text { (menit) }\end{array}$ \\
\hline Desember & 1,230 & 5 & 1,225 & 18,960 & 2,625 & 2,320 \\
Januari & 1,590 & 2 & 1,588 & 20,880 & 2,482 & 60 \\
Pebruari & 1,310 & 3 & 1,307 & 18,360 & 2,452 & 930 \\
Maret & 1,400 & 3 & 1,397 & 19,800 & 2,572 & 1,170 \\
April & 1,230 & 4 & 1,226 & 18,360 & 2,272 & 2,070 \\
Mei & 1,250 & 4 & 1,246 & 19,200 & 2,525 & 2,420 \\
Juni & 1,050 & 3 & 1,047 & 15,000 & 2,172 & 970 \\
Juli & 1,410 & 2 & 1,408 & 21,720 & 2,552 & 2,990 \\
Agustus & 1,275 & 4 & 1,271 & 20,880 & 2,662 & 3,660 \\
September & 1,240 & 3 & 1,237 & 20,040 & 2,412 & 3,490 \\
Oktober & 1,445 & 5 & 1,440 & 21,720 & 2,732 & 2,390 \\
Nopember & 1,325 & 3 & 1,322 & 20,040 & 2,592 & 2,290 \\
\hline Total & 15,755 & 41 & 15,714 & 234,960 & 30,050 & 24,760 \\
\hline Rata-rata & 1,313 & 3 & 1,310 & 19,580 & 2,504 & 2,063 \\
\hline
\end{tabular}

Sumber: Laporan perusahaan (2020)

Tabel 2 Keterangan Downtime Terencana

\begin{tabular}{|c|c|c|}
\hline \multicolumn{2}{|r|}{ Downtime Terencana } & $\begin{array}{c}\text { Total } \\
\text { Downtime }\end{array}$ \\
\hline 1 & Setting ulang axis $\mathrm{X}, \mathrm{Y}$ setiap 4 pcs & 19,580 \\
\hline 2 & Jadwal downtime rutin oleh maintenance & 1,560 \\
\hline 3 & Setting benda kerja,alat (ganti tipe) & 8,910 \\
\hline & Total & 30,050 \\
\hline
\end{tabular}

Sumber: Laporan perusahaan (2020)

Tabel 3 Keterangan Downtime Tidak Terencana

\begin{tabular}{clr}
\hline & Downtime Tidak Terencana & $\begin{array}{c}\text { Total } \\
\text { Downtime }\end{array}$ \\
\hline 1 & Alarm (emergency stop) axis z over travel & 10,820 \\
2 & Motor pompa Hidrolik Jebol & 8,600 \\
3 & Tidak bisa ganti alat (hidrolik spindel macet) & 2,860 \\
4 & Alarm Limit MXZ1 Zero Destance Proses TAP & 2,050 \\
5 & Lain-lain & 430 \\
\hline & & $\mathbf{2 4 , 7 6 0}$
\end{tabular}

Sumber: Laporan perusahaan (2020) 


\section{Hasil Perhitungan Nilai Overall Equipment Effectiveness (OEE)}

Overall Equipment Effectiveness (OEE) merupakan ukuran menyeluruh yang mengidentifikasikan tingkat produktivitas mesin/ peralatan dan kinerjanya. Pengukuran ini sangat penting untuk mengetahui area mana yang perlu untuk ditingkatkan produktivitas ataupun efisiensi mesin atau peralatan dan juga dapat menunjukkan area bottleneck yang terdapat pada lintasan produksi. Namun sebelum itu, beberapa factor perlu diketahui nilainya, yaitu;

\section{a. Availability Rate}

Merupakan suatu rasio yang menggambarkan pemanfaatan waktu yang tersedia untuk kegiatan operasi mesin atau peralatan. Pada availabilityrate ini sangat berhubungan erat dengan waktu efektif produksi dengan waktu downtime. Berikut perhitungannya, yaitu;

Availability Rate $=\frac{\text { Operating time }}{\text { Net available time }} \times 100 \%$

Dimana;

Operation time $\quad=$ Net available time - Downtime tidak terencana

Net available time $\quad=$ Total available time - Downtime terencana

Contoh Perhitungan Untuk Desember

Diketahui;

Total available time (AT)

Downtime terencana (PD)

Downtime tidak terencana (UD)

Net available time (NA)

Operation time (OT)

$$
\begin{aligned}
& =18,960 \text { menit } \\
& =2,625 \text { menit } \\
& =2,320 \text { menit } \\
& =\mathrm{AT}-\mathrm{PD}=18,960-2,625=16,335 \text { menit } \\
& =\mathrm{NA}-\mathrm{UD}=16,335-2,320=14,015 \text { menit }
\end{aligned}
$$

Maka, Availability Rate $=\frac{\text { operating time }}{\text { Net available time }} \times 100 \%=\frac{14,015}{16,335} \times 100 \%=85,80 \%$

b. Performance Rate

Merupakan ratio yang menggambarkan kemampuan dari peralatan dalam menghasilkan barang. Pada performance rate ini merupakan nilai dari hasil output\&capacity machine. Berikut perhitungannya, yaitu;

Performance Rate $=\frac{\text { Total Part Run } x \text { Ideal Cycle Time }}{\text { Operation Time }} \times 100 \%$

Dimana;

Total Part Run = Jumlah Produksi

Ideal Cycle Time $=$ Waktu siklus ideal

Operation time $=$ Net available time - Downtime tidak terencana 
Net available time $=$ Total available time - Downtime terencana

Contoh Perhitungan Untuk Desember

Diketahui;

Total available time (AT)

Downtime terencana (PD)

Downtime tidak terencana (UD)

Net available time (NA)

Operation time (OT)

Total Part Run

Ideal Cycle Time
$=18,960$ menit

$=2,625$ menit

$=2,320$ menit

$=\mathrm{AT}-\mathrm{PD}=18,960-2,625=16,335$ menit

$=\mathrm{NA}-\mathrm{UD}=16,335-2,320=14,015$ menit

$=1,230$ unit

$=10 \mathrm{menit} / \mathrm{unit}$

Maka,

Performance Rate $=\frac{\text { Total Part Run } x \text { Ideal Cycle Time }}{\text { Operation Time }} \times 100 \%$

Performance Rate $=\frac{1,230 \times 10}{14,015} \times 100 \%=87,76 \%$

\section{c. Quality Rate}

Merupakan rasio yang menggambarkan kemampuan peralatan dalam menghasilkan produk yang sesuai dengan standart. Dalam perhitungan QualityRate erat kaitannya dengan data jumlah produksi dan hasil yang berkualitas baik serta ada pula data produk reject dari hasil komponen yang dibuat. Berikut perhitungannya, yaitu;

Quality Rate $=\frac{\text { Total Part Run }- \text { Total Defect }}{\text { Total Part Run }} \times 100 \%$

Dimana;

Total Part Run = Jumlah Produksi

Total Defect $=$ Jumlah Produk Cacat

Contoh Perhitungan Untuk Desember

Diketahui;

Total Part Run $=1,230$ Unit

Total Defect $\quad=5$ Unit

Maka, Quality Rate $=\frac{\sum \text { Part Run }-\sum \text { Defect }}{\sum \text { Part Run }} \times 100 \%=\frac{1,230-5}{1,230} \times 100 \%=99,59 \%$

Untuk mengetahui tingkat efektivitas mesin CNC Miling secara keseluruhan pada perusahaan, maka formula yang digunakan yaitu:

$\mathrm{OEE}=$ Availability Rate $x$ Performance Rate $x$ Quality Rate

Contoh Perhitungan Untuk Desember 
$\mathrm{OEE}=$ Availability Rate $x$ Performance Rate $x$ Quality Rate

$\mathrm{OEE}=85,80 \% \times 87,76 \% \times 99,59 \%=74,99 \%$

Tabel 4 Perhitungan OEE Mesin CNC Miling MV40

Desember 2018 - November 2019

\begin{tabular}{lcccc}
\hline \multicolumn{1}{c}{ Bulan } & $\begin{array}{c}\text { Availability } \\
\text { Rate\% }\end{array}$ & $\begin{array}{c}\text { Perfomance } \\
\text { Rate\% }\end{array}$ & $\begin{array}{c}\text { Quality } \\
\text { Rate\% }\end{array}$ & OEE \% \\
\hline Desember & $85.80 \%$ & $87.76 \%$ & $99.59 \%$ & $74.99 \%$ \\
Januari & $99.67 \%$ & $86.71 \%$ & $99.87 \%$ & $86.31 \%$ \\
Februari & $94.15 \%$ & $87.46 \%$ & $99.77 \%$ & $82.16 \%$ \\
Maret & $93.21 \%$ & $87.18 \%$ & $99.79 \%$ & $81.09 \%$ \\
April & $87.13 \%$ & $87.74 \%$ & $99.67 \%$ & $76.21 \%$ \\
Mei & $85.49 \%$ & $87.69 \%$ & $99.68 \%$ & $74.72 \%$ \\
Juni & $92.44 \%$ & $88.55 \%$ & $99.71 \%$ & $81.62 \%$ \\
Juli & $84.40 \%$ & $87.16 \%$ & $99.86 \%$ & $73.46 \%$ \\
Agustus & $79.91 \%$ & $87.58 \%$ & $99.69 \%$ & $69.77 \%$ \\
September & $80.20 \%$ & $87.71 \%$ & $99.76 \%$ & $70.17 \%$ \\
Oktober & $87.41 \%$ & $87.06 \%$ & $99.65 \%$ & $75.84 \%$ \\
November & $86.88 \%$ & $87.41 \%$ & $99.77 \%$ & $75.77 \%$ \\
\hline Rata - rata & $88.06 \%$ & $87.50 \%$ & $99.74 \%$ & $76.84 \%$ \\
\hline
\end{tabular}

Sumber: Pengolahan Data (2020)

Pada Tabel 4 dapat diketahui besar nilai rata-rata OEE adalah 76.84\%, nilai ini tidak memenuhi ketetapan standar nilai OEE yaitu $85 \%$. Nilai OEE tertinggi berada pada Januari yaitu sebesar $86.31 \%$ dan nilai OEE terendah pada Agustus yaitu sebesar 69.77\%. Nilai availability rate adalah yang paling berpengaruh pada rendahnya nila OEE pada Agustus 2019.

\section{Analisa Data}

a. Diagram Pareto

Berdasarkan data downtime mesin CNC milingmv40 yang didapat periode Desember 2018 hingga November 2019, diketahui bahwa kerusakan yang terjadi dikategorikan menjadi 5 downtime yaitu :

Tabel 5 Keterangan Downtime Tidak Terencana

\begin{tabular}{clc}
\hline & Downtime Tidak Terencana & Total \\
& Downtime & 10,820 \\
\hline 1 & Alarm (emergency stop) axis $z$ over travel & 8,600 \\
2 & Motor pompa Hidrolik Jebol & 2,860 \\
3 & Tidak bisa ganti alat (hidrolik spindel macet) & 2,050 \\
4 & Alarm Limit MXZ1 Zero Destance Proses TAP & 430 \\
5 & Lain-lain & $\mathbf{2 4 , 7 6 0}$ \\
\hline \multicolumn{2}{c}{ Total }
\end{tabular}


Setelah mengetahui downtime yang terjadi, digunakan diagram pareto untuk melihat penyebab utama masalah dengan cara mengklasifikasikan masalah tersebut ke dalam bentuk persen kumulatif.

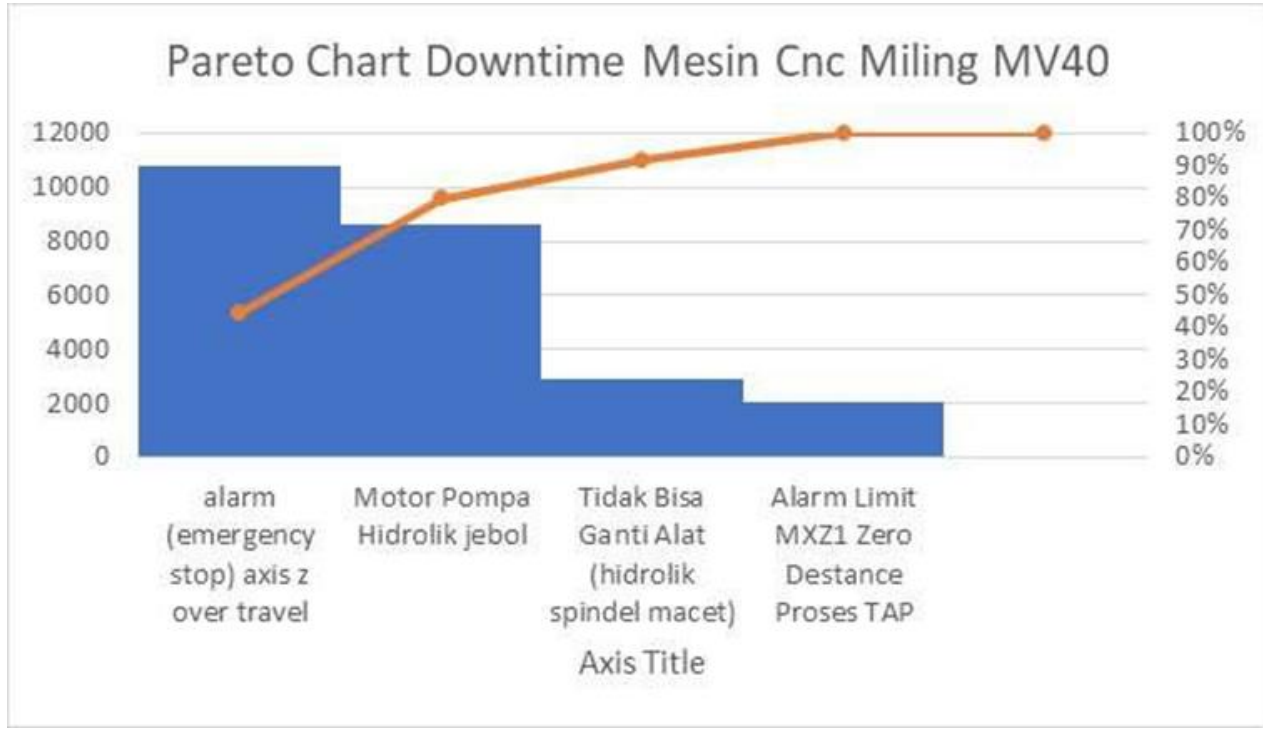

Sumber: Olah Data (2020)

Gambar 1 Diagram Pareto Downtime Mesin CNC Miling MV40

Dari diagram pada gambar 2 dapat dilihat bahwa faktor penyebab terbesar adalah masalah :

1. Alarm (emergency stop) axis $z$ over travel hal ini disebabkan switch limit sensor $Z$ melewati batas maksimal sehingga PLC memutus arus agar servo drive berhenti bergerak dan mengunci.

2. Motor pompa hidrolik jebol, disebabkan oleh oli pelumas hidrolik yang kering karna adanya kebocoran yang tidakdiketahui dan komponen gasket, o-ring yang sudah mulai getas.

b. Diagram Sebab Akibat

Agar perbaikan dapat segera dilakukan, maka analisa terhadap penyebab faktor- faktor yang mengakibatkan rendahnya efektivitas mesin dalam perhitungan OEE dilakukan dengan menggunakan diagram sebab akibat (fishbone). Setelah mengetahui penyebab yang memiliki kontribusi besar pada efektivitas mesin tersebut, berdasarkan hasil diagram pareto 2 jenis downtime terbesar adalah alarm (emergency stop) axis $\mathrm{z}$ over travel $44 \%$ dan Motor pompa hidrolik jebol 35\% menjadi fokus permasalahan yang akan dibahas selanjutnya. Oleh karena itu downtime tersebut akan dianalisa dengan diagram sebab akibat untuk mengetahui akar permasalahan yang terjadi. 


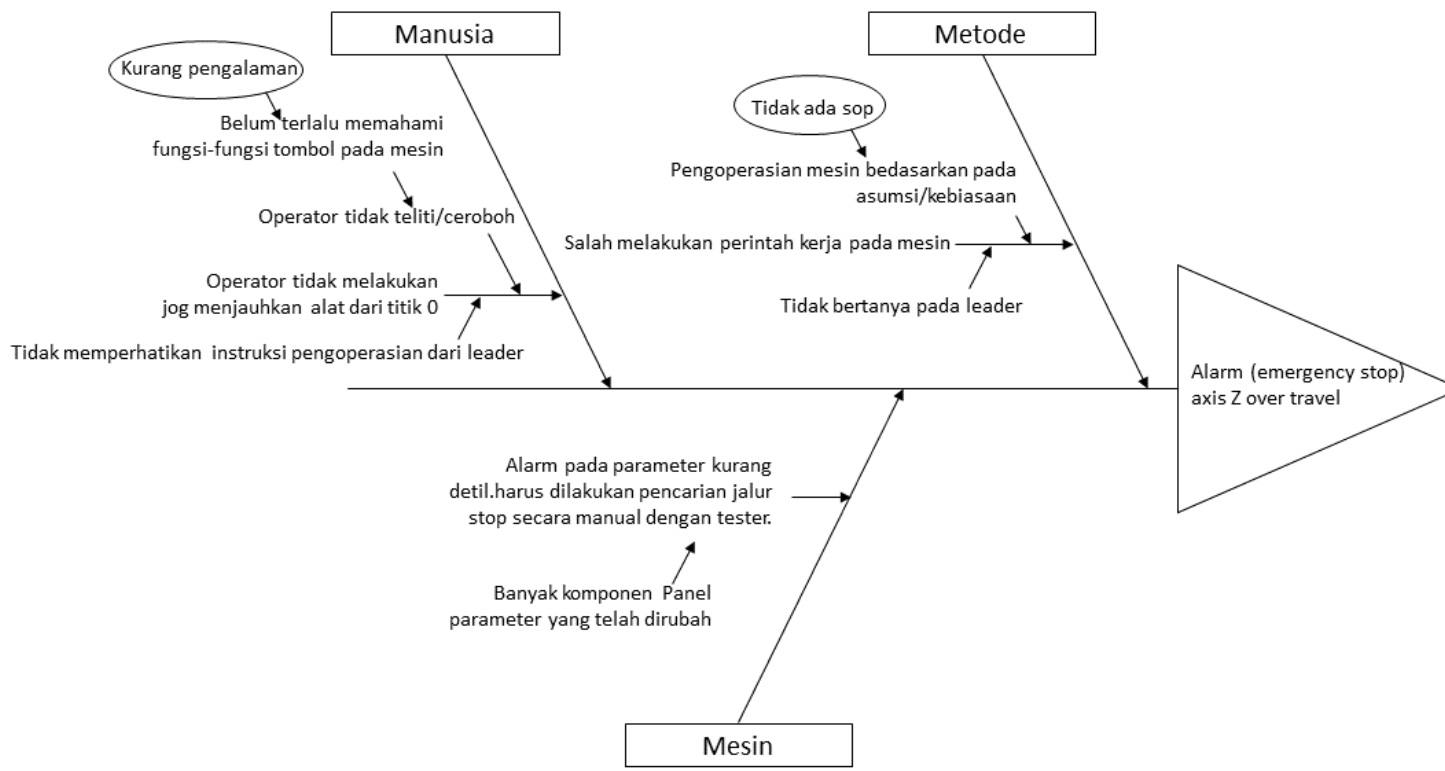

Gambar 2 Diagram Fishbone untuk Alarm (Emergency Stop) Axis Z Over Travel

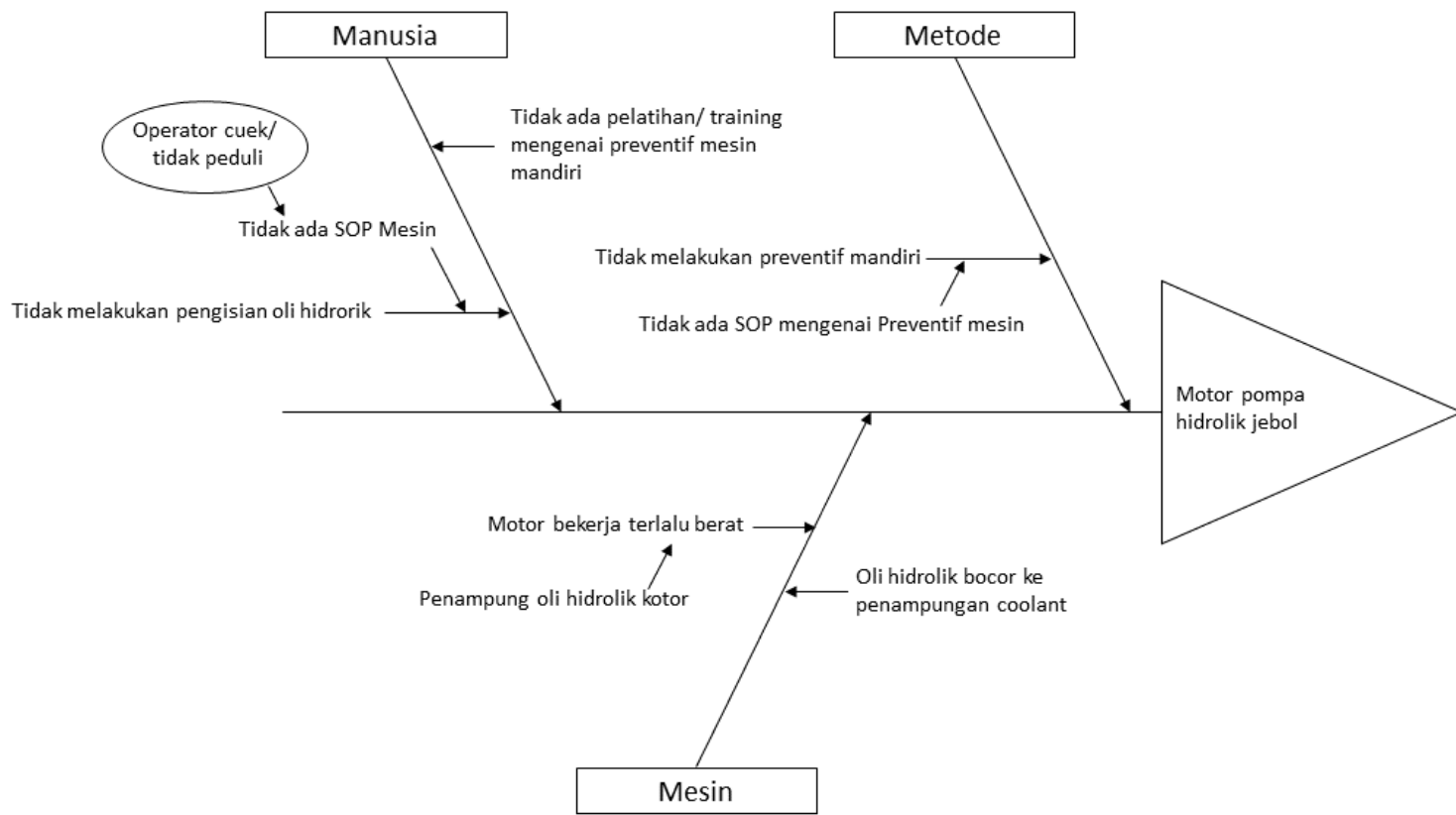

Gambar 3 Diagram Fishbone untuk Motor Pompa Hidrolik Jebol

Dari data hasil pembahasan pada Gambar 2 dan Gambar 3, ditemukan faktor penyebab utama downtime terbesar pada mesin CNC miling MV40, yaitu; kurangnya pengalaman, pperator cuek / tidak peduli, dan tidak ada SOP. Data faktor penyebab utama downtime terbesar selanjutnya akan diolah untuk membuat usulan perbaikan mengggunakan metode $5 \mathrm{~W}+1 \mathrm{H}$.

c. Usulan perbaikan dengan $5 \mathrm{~W}+1 \mathrm{H}$ 
Berdasarkan analisa dari diagram fishbone yang telah dibuat, data tersebut digunakan untuk membuat usulan perbaikan menggunakan $5 \mathrm{~W}+1 \mathrm{H}$. Berikut rincian perbaikannya.

\begin{tabular}{|c|c|c|c|c|c|c|c|}
\hline \multirow[b]{2}{*}{ No } & & WHY & WHAT & WHERE & WHEN & WHO & HOW \\
\hline & Masalah & $\begin{array}{c}\text { Mengapa } \\
\text { Perlu } \\
\text { Dilakukan } \\
\text { Perbaikan }\end{array}$ & $\begin{array}{c}\text { Apa } \\
\text { Yang } \\
\text { Harus } \\
\text { Dilaku } \\
\text { kan }\end{array}$ & $\begin{array}{c}\text { Dimana } \\
\text { Melakuka } \\
\text { nPerbaika } \\
\text { n }\end{array}$ & $\begin{array}{c}\text { Kapan } \\
\text { Dilakukan } \\
\text { Perbaikan }\end{array}$ & $\begin{array}{l}\text { Siapa Yang } \\
\text { Melakukan } \\
\text { Perbaikan }\end{array}$ & $\begin{array}{c}\text { Bagimana } \\
\text { Melakukan } \\
\text { nya }\end{array}$ \\
\hline \multicolumn{8}{|c|}{ Manusia } \\
\hline 1 & $\begin{array}{l}\text { Kurang } \\
\text { pengala } \\
\text { man }\end{array}$ & $\begin{array}{l}\text { Agar tidak } \\
\text { terjadi } \\
\text { kesalahan } \\
\text { yang sama }\end{array}$ & $\begin{array}{l}\text { Harus } \\
\text { memperhat } \\
\text { ikan SOP }\end{array}$ & $\begin{array}{l}\text { Bagian } \\
C N C \\
\text { miling }\end{array}$ & $\begin{array}{l}\text { Segera } \\
\text { mungkin }\end{array}$ & $\begin{array}{l}\text { Operator } \\
C N C\end{array}$ & $\begin{array}{l}\text { Lebih hati- } \\
\text { hati pada } \\
\text { setiap } \\
\text { pegoperasia } \\
\text { n mesin, } \\
\text { memperhati } \\
\text { kan } \\
\text { instruksi } \\
\text { dari leader } \\
\text { team, dan } \\
\text { mengikuti } \\
\text { standar } \\
\text { pengoperasi } \\
\text { an mesin } \\
\text { SOP }\end{array}$ \\
\hline 2 & $\begin{array}{l}\text { Operator } \\
\text { cuek/tida } \\
\text { k peduli }\end{array}$ & $\begin{array}{l}\text { Agar tidak } \\
\text { terjadi lagi } \\
\text { problem } \\
\text { yang sama }\end{array}$ & $\begin{array}{l}\text { Perlu } \\
\text { dilakukan } \\
\text { Training } \\
\text { mengenai } \\
\text { perawatan }\end{array}$ & $\begin{array}{l}\text { Operator } \\
\text { CNC }\end{array}$ & $\begin{array}{l}\text { Segera } \\
\text { mungkin }\end{array}$ & $\begin{array}{l}\text { Divisi HR dan } \\
\text { Maintenance }\end{array}$ & $\begin{array}{l}\text { Dilakukan } \\
\text { penjadwalan } \\
\text { training yang } \\
\text { membahas } \\
\text { tentang } \\
\text { preventif } \\
\text { mesin } \\
\text { mandiri }\end{array}$ \\
\hline \multicolumn{8}{|c|}{ Metode } \\
\hline 3 & $\begin{array}{l}\text { Tidak ada } \\
\text { SOP } \\
\text { pengoper } \\
\text { asian } \\
\text { mesin }\end{array}$ & $\begin{array}{l}\text { Agar } \\
\text { menjadi } \\
\text { acuan kerja } \\
\text { dalam } \\
\text { pengoperasi } \\
\text { an mesin } \\
C N C \text { miling }\end{array}$ & $\begin{array}{l}\text { Membuat } \\
\text { SOP } \\
\text { pengopera } \\
\text { sian mesin }\end{array}$ & $\begin{array}{l}\text { Di bagian } \\
C N C \\
\text { miling }\end{array}$ & $\begin{array}{l}\text { Segera } \\
\text { mungkin }\end{array}$ & $\begin{array}{l}\text { Divisi } \\
\text { maintenance } \\
\text { development }\end{array}$ & $\begin{array}{l}\text { Membuat } \\
\text { susunan } \\
\text { kerja } \\
\text { pengoperasi } \\
\text { an mesin } \\
\text { dan } \\
\text { perawatan } \\
\text { mesin } \\
\text { (automous } \\
\text { maintenanc } \\
\text { e), } \\
\text { melakukan } \\
\text { wawancara } \\
\text { kepada } \\
\text { tenaga ahli } \\
\text { (leader). }\end{array}$ \\
\hline
\end{tabular}

Sumber: Data diolah (2020) 


\section{SIMPULAN DAN SARAN}

Berdasarkan dari hasil pengamatan yang telah dilakukan untuk menemukan tingkat efektivitas (OEE) pada mesin $C N C$ miling MV40 di dapatkan kesimpulan sebagai berikut :

a. Nilai Overall Equipment Effectiveness (OEE) mesin CNC miling MV40periode Desember 2018 - November 2019 adalah 76.84\% nilai tersebut dibawah standart OEE world class. Penyebab dari rendahnya nilai tersebut adalah availability \& performance yang tidak memenuhi standar. Nilai availability rate sebesar $88.06 \%$ dan nilai performance rate sebesar $87.50 \%$ sedangkan standart OEE world lean siqma enterprise sebesar $\geq 90 \%$ untuk availability rate dan performance rate $\geq 95 \%$. Dari nilai tersebut dapat diketahui bagaimana kondisi aktual mesin dalam menghasilkan produk.

b. Berdasarkan hasil dengan menggunakan diagram fishbone diperoleh bahwa faktor dominan dalam menghasilkan rendahnya nilai OEE yaitu disebabkan oleh Alarm (Emergency Stop) Axis Z Over Travel dan Motor Pompa Hidrolik Jebol dengan akar permasalahan ada pada faktor manusia seperti kurang pengalaman dan operator cuek/tidak peduli, dan faktor metode seperti Tidak ada SOP pengoperasian mesin.

\section{DAFTAR PUSTAKA}

Habib, A. S., \& Supriyanto, H. har. (2012). Pengukuran Nilai Overall Equipment Effectiveness ( OEE ) Sebagai Pedoman Perbaikan Efektivitas Mesin CNC Cutting. Jurnal Teknik Pomits, 1(1), 1-6.

Nakajima, S. (1988). Implementing Total Productive Maintenance. Productivity Press, Inc. Rinawati, D. I., \& Dewi, C. N. (2014). Total productive maintenance. SAE Technical Papers, 21-26. https://doi.org/10.4271/982092

Williamson, R. . (2006). Using Overall Equipment Effectiveness: the Metric and the Measures. http://www.swspitcrew.com 